\title{
The safety of vasopressor-induced hypertension in subarachnoid hemorrhage patients with coexisting unruptured, unprotected intracranial aneurysms
}

\author{
Matthew R. Reynolds, MD, PhD, ${ }^{1}$ Robert T. Buckley, MD, ${ }^{1}$ Santoshi S. Indrakanti, MD, ${ }^{1}$ \\ Ali H. Turkmani, MD, ${ }^{2}$ Gerald Oh, MD, ${ }^{2}$ Emanuela Crobeddu, MD, ${ }^{3}$ Kyle M. Fargen, MD, MPH, ${ }^{4}$ \\ Tarek Y. El Ahmadieh, MD, ${ }^{5}$ Andrew M. Naidech, MD, MSPH, ${ }^{5}$ Sepideh Amin-Hanjani, MD, ${ }^{2}$ \\ Giuseppe Lanzino, MD, ${ }^{3}$ Brian L. Hoh, MD, ${ }^{4}$ Bernard R. Bendok, MD, MS, ${ }^{5}$ and \\ Gregory J. Zipfel, MD'
}

\begin{abstract}
1Department of Neurological Surgery, Washington University Medical School, St. Louis, Missouri; 2Department of Neurological Surgery, University of Illinois at Chicago, Illinois; ${ }^{2}$ Department of Neurological Surgery, Mayo Clinic, Rochester, Minnesota; ${ }^{4}$ Department of Neurological Surgery, University of Florida, Gainesville, Florida; and ${ }^{5}$ Department of Neurosurgery, Northwestern University Feinberg School of Medicine, Chicago, Illinois
\end{abstract}

\begin{abstract}
OBJECT Vasopressor-induced hypertension $(\mathrm{VIH})$ is an established treatment for patients with aneurysmal subarachnoid hemorrhage (SAH) who develop vasospasm and delayed cerebral ischemia (DCl). However, the safety of VIH in patients with coincident, unruptured, unprotected intracranial aneurysms is uncertain.
\end{abstract}

METHODS This retrospective multiinstitutional study identified 1) patients with aneurysmal SAH and 1 or more unruptured, unprotected aneurysms who required $\mathrm{VIH}$ therapy ( $\mathrm{VIH}$ group), and 2) patients with aneurysmal SAH and 1 or more unruptured, unprotected aneurysms who did not require $\mathrm{VIH}$ therapy (non-VIH group). All patients had previously undergone surgical or endovascular treatment for the presumed ruptured aneurysm. Comparisons between the $\mathrm{VIH}$ and non-VIH patients were made in terms of the patient characteristics, clinical and radiographic severity of SAH, total number of aneurysms, number of ruptured/unruptured aneurysms, aneurysm location/size, number of unruptured and unprotected aneurysms during $\mathrm{VIH}$, severity of vasospasm, degree of hypervolemia, and degree and duration of $\mathrm{VIH}$ therapy.

RESULTS For the VIH group ( $n=176$ ), 484 aneurysms were diagnosed, 231 aneurysms were treated, and 253 unruptured aneurysms were left unprotected during 1293 total days of $\mathrm{VIH}$ therapy $(5.12$ total years of $\mathrm{VIH}$ therapy for unruptured, unprotected aneurysms). For the non-VIH group $(n=73), 207$ aneurysms were diagnosed, 93 aneurysms were treated, and 114 unruptured aneurysms were left unprotected. For the $\mathrm{VIH}$ and non-VIH groups, the mean sizes of the ruptured $(7.2 \pm 0.3$ vs $7.8 \pm 0.6 \mathrm{~mm}$, respectively; $p=0.27)$ and unruptured $(3.4 \pm 0.2 \mathrm{vs} 3.2 \pm 0.2 \mathrm{~mm}$, respectively; $p=$ 0.40 ) aneurysms did not differ. The authors observed 1 new SAH from a previously unruptured, unprotected aneurysm in each group ( 1 of 176 vs 1 of 73 patients; $p=0.50$ ). Baseline patient characteristics and comorbidities were similar between groups. While the degree of hypervolemia was similar between the $\mathrm{VIH}$ and non-VIH patients (fluid balance over the first 10 days of therapy: $3146.2 \pm 296.4$ vs $2910.5 \pm 450.7 \mathrm{ml}$, respectively; $p=0.67$ ), VIH resulted in a significant increase in mean arterial pressure (mean increase over the first 10 days of therapy relative to baseline: $125.1 \% \pm 1.0 \%$ vs $98.2 \% \pm 1.2 \%$, respectively; $p<0.01)$ and systolic blood pressure $(125.6 \% \pm 1.1 \%$ vs. $104.1 \% \pm 5.2 \%$, respectively; $p$ $<0.01$ ).

CONCLUSIONS For small, unruptured, unprotected intracranial aneurysms in SAH patients, the frequency of aneurysm rupture during $\mathrm{VIH}$ therapy is rare. The authors do not recommend withholding $\mathrm{VIH}$ therapy from these patients.

http://thejns.org/doi/abs/10.3171/2014.12.JNS141201

KEY WORDS subarachnoid hemorrhage; delayed cerebral ischemia; vasospasm; induced hypertension; triple-H therapy; unruptured; unprotected; intracranial aneurysm; vascular disorders

\footnotetext{
ABBREVIATIONS ACA = anterior cerebral artery; $\mathrm{DCl}=$ delayed cerebral ischemia; DVT/PE = deep vein thrombosis/pulmonary embolism; ICA = internal carotid artery; $\mathrm{MAP}=$ mean arterial pressure; $\mathrm{MCA}=$ middle cerebral artery; $\mathrm{SAH}=$ subarachnoid hemorrhage; $\mathrm{SBP}=$ systolic blood pressure; $\mathrm{SEM}=$ standard error of the mean; VIH = vasopressor-induced hypertension; WFNS $=$ World Federation of Neurosurgical Societies.

SUBMITTED May 30, 2014. ACCEPTED December 30, 2014.

INCLUDE WHEN CITING Published online July 24, 2015; DOI: 10.3171/2014.12.JNS141201.

DISCLOSURE Dr. Zipfel reports that he has received a grant-in-aid from the American Heart Association and a grant from the Barnes-Jewish Hospital Foundation. Dr. Lanzino reports that he is a consultant for ev3/Covidien, Codman/Johnson and Johnson, and Edge Therapeutics.
} 
$\mathrm{A}$ NEURYSMAL subarachnoid hemorrhage (SAH) is a form of hemorrhagic stroke that is associated with significant morbidity and mortality. ${ }^{15}$ Following aneurysmal SAH, prompt treatment of the ruptured aneurysm is recommended in order to prevent rebleeding and permit aggressive treatment of vasospasm-induced delayed cerebral ischemia (DCI) using vasopressor-induced hypertension (VIH) therapy, should the latter occur. However, $19 \%-34 \%$ of SAH patients harbor multiple intracranial aneurysms, $, 14,17,20$ and many of these are not amenable to treatment during the same session as the ruptured aneurysm. Therefore, the clinical scenario frequently exists where SAH patients with multiple intracranial aneurysms have the ruptured aneurysm treated while the unruptured aneurysms remain untreated. While VIH therapy is the treatment of choice for vasospasm-induced DCI, ${ }^{21}$ the safety of this practice in SAH patients with coexisting unruptured, untreated aneurysms has yet to be firmly established. To address this question, we conducted this large, multiinstitutional, retrospective study to examine the safety of VIH in SAH patients harboring unruptured, unprotected intracranial aneurysms.

\section{Methods \\ Patient Selection}

We performed this retrospective, multiinstitutional chart review to identify patients who were treated between 2000 and 2013 and had 1) aneurysmal SAH and 1 or more unruptured, unprotected aneurysms who developed vasospasm that required VIH (VIH group), or 2) aneurysmal SAH and 1 or more unruptured, unprotected aneurysms who did not require VIH (non-VIH group). Data from the VIH patients were collected from 5 major neurosurgical referral centers in the United States: Washington University in St. Louis (primary study center; St. Louis, Missouri), University of Illinois (Chicago, Illinois), Mayo Clinic (Rochester, Minnesota), University of Florida (Gainesville, Florida), and Northwestern University (Chicago, Illinois). Data from the non-VIH patients were collected from the primary study center.

Collected data included patient age, comorbidities, timing of the antiplatelet and anticoagulant medical therapies, clinical and radiographic severity of SAH, total number of aneurysms, number of ruptured and unruptured aneurysms, aneurysm location, aneurysm size, aneurysm treatment modalities, number of unruptured/unprotected aneurysms during VIH, method for diagnosing vasospasm, severity of vasospasm, endovascular treatment for vasospasm, degree of hypervolemia, degree of VIH, duration of $\mathrm{VIH}$, vasopressor used to achieve hypertension, and patient disposition upon discharge. These data were transferred to a standardized form and sent to the primary study center for interpretation and analysis. Institutional Review Board and Human Resource Protection Agency approval was obtained at each institution prior to data collection.

\section{Management of SAH}

All patients were admitted to a neurosurgical intensive care unit or high-dependency ward for assessment. Noncontrast head CT was performed upon admission. Based on the clinical and radiographic evidence of hydrocephalus, CSF diversion (e.g., ventriculostomy or subarachnoid lumbar drain) was performed. All patients received cerebral angiography-in the form of either a catheter angiogram, CT angiogram, or MR angiogram-prior to aneurysm treatment. The location of the ruptured aneurysm was determined by consensus between the treating neurosurgeon and neuroradiologist based on the clinical evidence (e.g., focal motor deficits, cranial nerve palsy) and radiographic evidence (e.g., laterality and location of SAH, size, morphology, and location of the aneurysm).

Surgical management of the patients with a ruptured aneurysm consisted of open microsurgical clipping or endovascular coil embolization. The decision to clip or coil was determined on a case-by-case basis by a multidisciplinary team of cerebrovascular neurosurgeons, endovascular neurosurgeons, and/or interventional neuroradiologists and was influenced by the aneurysm (size, location, neck width) and patient (comorbidities, neurological status) characteristics. Oftentimes, other unruptured aneurysms were treated during the initial procedure if the unruptured aneurysms were easily accessible. In some cases, the ruptured aneurysm was confirmed during the open microsurgical clipping procedure. In the event that the presumed ruptured aneurysm was unruptured during the open procedure, the remaining aneurysms were expeditiously treated during the same, or separate, sessions. Early treatment of the ruptured aneurysms $(<24$ hours) was the goal in order to prevent rebleeding and permit aggressive treatment of vasospasm-induced DCI, unless the patient's neurological status precluded immediate therapy.

Nimodipine therapy was administered to all patients. Vital signs (heart rate, blood pressure, and oxygen saturation) were recorded at least every 30 minutes. Mean arterial pressure (MAP) and systolic blood pressure (SBP) were measured using arterial catheterization or cuff pressure. All patients were hydrated with intravenous crystalloids, colloids, and/or blood products to maintain a state of euvolemia or hypervolemia. For patients with cardiopulmonary morbidities, the degree of hypervolemia was carefully monitored to prevent fluid overload. Strict fluid monitoring was performed at least hourly. The degree of hydration was determined based on the clinical findings (e.g., fluid balance, heart rate, urine output, and skin turgor $)^{3,23}$ and supplemented in some cases by central venous pressure recordings from an indwelling central venous catheter.

For the statistical analyses, fluid balance was calculated daily for the VIH patients during the first 10 days of induced hypertension and compared with the daily fluid balance of the non-VIH patients during Days 6-16 of hospital admission. Posthemorrhage Day 6 was chosen as the starting date for the non-VIH group, given that the average start time of VIH therapy was posthemorrhage Day 6.39 \pm 0.27 . Similarly, MAP and SBP were averaged every 8 hours for the VIH patients during the first 10 days of VIH therapy and compared with the average MAP and SBP values of the non-VIH patents during Days 6-16 of hospital admission, respectively. These values were reported as a percentage change from baseline (for VIH patients, baseline was the average of the 3 hours prior to VIH; for non-VIH patients, baseline was the average of the 3 
hours prior to data collection on posthemorrhage Day 6). For the VIH $(n=73)$ and non-VIH patients $(n=73)$ from the Washington University in St. Louis cohort, the average MAP on admission (taken as the average of the first 3 blood pressure measurements) was also measured and compared between groups.

In the setting of a new, focal, neurological deficit, head CT was performed. DCI was defined as a decreased level of consciousness or new neurological deficit occurring 2-14 days following SAH that could not be attributed to other causes (e.g., hematoma, hydrocephalus, intracerebral edema, seizure, or metabolic/biochemical disturbance). In most cases, the diagnosis of vasospasm-induced DCI was established by catheter angiography, CT angiography, MR angiography, or transcranial Doppler ultrasonography.

VIH was initiated by raising the patient's MAP by $10 \%-15 \%$ above baseline determined over the previous 3 hours using vasopressor agents or until neurological improvement was observed. The hemodynamic parameters of VIH were ultimately determined by the treating neurovascular surgeon and adjusted on a case-by-case basis. VIH therapy was maintained until the patient's neurological deficit had resolved/stabilized or imaging showed the resolution of cerebral vasospasm. Thereafter, VIH was slowly weaned as allowed by the patient's neurological status. VIH therapy was often supplemented with endovascular therapies, including intraarterial vasodilatory medications and transluminal balloon angioplasty with or without stenting.

\section{Statistical Analysis}

Categorical variables are displayed as counts and rates, and continuous variables are displayed as the mean \pm standard error of the mean (SEM). We compared groups using the generalized Fisher exact test for categorical variables or the 2-tailed Student t-test for continuous variables that were approximately normally distributed. The level of statistical significance was set at $\mathrm{p}<0.05$.

\section{Results}

\section{Patient Characteristics}

We retrospectively identified $176 \mathrm{VIH}$ patients and 73 non-VIH patients. The mean ages at presentation for the $\mathrm{VIH}$ and non-VIH groups were $54.5 \pm 0.9$ and $53.8 \pm 1.7$ years, respectively $(\mathrm{p}=0.66)$ (Table 1$)$. The percentages of female patients in the VIH and non-VIH groups were $79.5 \%$ (140 of 176 patients) and 80.8\% (59 of 73 patients), respectively $(\mathrm{p}=0.82)$. Medical comorbidities were evenly distributed between groups (Table 1). However, there were significantly more patients with preexisting, medically treated hypertension in the non-VIH group than the VIH group (32 of 73 patients [43.8\%] vs 53 of 176 patients $[30.1 \%]$ ), respectively; $p=0.04)$.

\section{Anticoagulant/Antiplatelet Therapy}

For the VIH group, we ascertained if anticoagulant/antiplatelet therapies were administered prior to, or during, VIH therapy. For the non-VIH group, we determined if these medications were taken prior to, or during, neurosurgical hospital admission. In the non-VIH group, any medications administered during aneurysm treatment (e.g., heparin and/or antiplatelet therapy for endovascular embolization) were categorized as "before" treatment. Overall, the timing for antiplatelet and anticoagulant medical therapy was similar between groups (Table 1). However, there were more patients in the VIH group receiving anticoagulants during VIH therapy than in the non-VIH group (21 [11.9\%] vs 2 [2.7\%], respectively; $p=0.02$ ), and more patients receiving heparin deep vein thrombosis/pulmonary embolism (DVT/PE) prophylaxis before VIH in the non-VIH group than in the VIH group (68 [93.2\%] vs 144 [81.8\%], respectively; $\mathrm{p}=0.02$ ).

\section{Clinical Presentation}

The clinical severity of SAH was greater in the VIH group than in the non-VIH group, as determined by the Hunt and Hess grade $^{9}(2.94 \pm 0.07$ vs $2.63 \pm 0.10$, respectively; $\mathrm{p}=0.02$ ) and World Federation of Neurosurgical Societies (WFNS) SAH grade $(2.59 \pm 0.09$ vs $2.16 \pm 0.11$, respectively; $p=0.01$ ) upon admission (Fig. 1). The extent of radiographic $\mathrm{SAH}$, as assessed using the modified Fisher scale, ${ }^{7}$ was also greater in the VIH group than the non-VIH group ( $3.2 \pm 0.06$ vs $2.75 \pm 0.10$, respectively; $p$ $<0.01$ ) (Fig. 1).

\section{Indications for $\mathrm{VIH}$}

Indications for VIH included DCI (82.4\%), poor neurological examination (23.9\%), prophylaxis (11.4\%), and/ or asymptomatic vasospasm demonstrated on catheter angiography (86.9\%), MR angiography $(0.6 \%)$, CT angiography (10.8\%), or transcranial Doppler ultrasonography $(47.2 \%)$. Some patients fell into more than 1 category.

\section{Severity, Location, and Treatment of Vasospasm}

Radiographic vasospasm was categorized as mild $(0 \%-33 \%)$, moderate $(34 \%-66 \%)$, or severe $(67 \%-100 \%$; i.e., flow limiting). ${ }^{24}$ For the VIH patients, radiographic vasospasm was mild in 23 patients (13.1\%), moderate in 66 patients (37.5\%), and severe in 87 patients (49.4\%). Radiographic vasospasm involved the anterior circulation in 173 patients $(98.3 \%)$ and posterior circulation in 32 patients $(18.2 \%)$.

Vasopressors were initiated on posthemorrhage Day $6.39 \pm 0.27$, and $\mathrm{VIH}$ patients were treated for a mean duration of $7.35 \pm 0.27$ days (total of 1293.4 days, or 3.54 years). Cumulative VIH treatment time was 1870.6 days, or 5.12 years (i.e., 1293.4 days $\times 1.44$ mean unruptured, unprotected aneurysms per VIH patient). The vasopressors used included Levophed in 92 patients (52.2\%), Neo-Synephrine in 138 patients (78.4\%), dopamine in 15 patients $(8.5 \%)$, dobutamine in 1 patient $(0.6 \%)$, and milrinone in 11 patients (6.2\%). Endovascular vasodilator therapy was administered to 102 patients (58.0\%), while angioplasty with or without stenting was performed on 70 patients $(39.8 \%)$.

In the non-VIH group, DCI was observed in 11 patients $(15.1 \%)$ who were not treated with VIH. In this group, radiographic vasospasm was absent in 12 patients (16.4\%), mild in 25 patients $(34.2 \%)$, moderate in 32 patients (43.8\%), and severe in 4 patients (5.5\%). Angiographic vasospasm involved the anterior circulation in 71 patients (97.3\%) and posterior circulation in 11 patients (15.1\%). 
TABLE 1. Patient characteristics*

\begin{tabular}{|c|c|c|c|}
\hline & $\mathrm{VIH}(n=176)$ & Non-VIH $(n=73)$ & p Value \\
\hline Mean age (yrs) & $54.5 \pm 0.9$ & $53.8 \pm 1.7$ & 0.66 \\
\hline \multicolumn{4}{|l|}{ Sex } \\
\hline Male & $36(20.5)$ & $14(19.2)$ & 0.82 \\
\hline Female & $140(79.5)$ & $59(80.8)$ & 0.82 \\
\hline \multicolumn{4}{|l|}{ Comorbidities } \\
\hline HTN (not on medication) & $28(15.9)$ & $18(24.7)$ & 0.11 \\
\hline HTN (on medication) & $53(30.1)$ & $32(43.8)$ & 0.04 \\
\hline NIDDM (on medication) & $18(10.2)$ & $6(8.2)$ & 0.63 \\
\hline HL (on medication) & $25(14.2)$ & $17(23.3)$ & 0.08 \\
\hline Drug use (current) & $19(10.8)$ & $11(15.1)$ & 0.35 \\
\hline Drug use (prior) & $13(7.4)$ & $7(9.6)$ & 0.56 \\
\hline Smoker (current) & $116(65.9)$ & $50(68.5)$ & 0.69 \\
\hline Smoker (prior) & $51(29.0)$ & $16(21.9)$ & 0.25 \\
\hline \multicolumn{4}{|l|}{ Medications } \\
\hline Antiplatelet therapy before $\mathrm{VIH} \dagger$ & $36(20.5)$ & $17(23.3)$ & 0.62 \\
\hline Antiplatelet therapy during VIH $\ddagger$ & $39(22.2)$ & $17(23.3)$ & 0.85 \\
\hline Anticoagulant therapy before $\mathrm{VIH} \dagger$ & $47(26.7)$ & $26(35.6)$ & 0.16 \\
\hline Anticoagulant therapy during VIH $\ddagger$ & $21(11.9)$ & $2(2.7)$ & 0.02 \\
\hline Heparin DVT/PE prophylaxis before VIH† & $144(81.8)$ & $68(93.2)$ & 0.02 \\
\hline Heparin DVT/PE prophylaxis during VIH $\ddagger$ & $153(86.9)$ & $68(93.2)$ & 0.16 \\
\hline Heparin DVT/PE therapy before VIH† & $1(0.6)$ & $0(0.0)$ & 1.00 \\
\hline Heparin DVT/PE therapy during VIH $\ddagger$ & $3(1.7)$ & $1(1.4)$ & 1.00 \\
\hline Lovenox DVT/PE prophylaxis beforeVIH† & $0(0.0)$ & $0(0.0)$ & 1.00 \\
\hline Lovenox DVT/PE prophylaxis during VIH & $0(0.0)$ & $0(0.0)$ & 1.00 \\
\hline Lovenox DVT/PE therapy before VIH† & $0(0.0)$ & $0(0.0)$ & 1.00 \\
\hline Lovenox DVT/PE therapy during VIH & $3(1.1)$ & $0(0.0)$ & 0.56 \\
\hline
\end{tabular}

$\mathrm{HL}$ = hyperlipidemia; $\mathrm{HTN}=$ hypertension; NIDDM = noninsulin-dependent diabetes mellitus.

* The mean value is presented as the mean \pm SEM. All other non-p values represent the number of patients (\%). Values in boldface are statistically significant.

$\dagger$ For the non-VIH group, denotes medical therapy before admission or during aneurysm treatment.

$\ddagger$ For the non-VIH group, denotes medical therapy after aneurysm treatment.

Endovascular vasodilator therapy was performed in 12 patients (16.4\%) and angioplasty with or without stenting was performed in 3 patients $(4.1 \%)$.

\section{Aneurysm Characteristics}

The total number of aneurysms diagnosed in the VIH and non-VIH groups was 484 and 207, respectively (Table 2). The percentage of ruptured aneurysms did not differ between the VIH and non-VIH groups $(37.6 \%$ [182] vs $35.7 \%$ [74], respectively; $p=0.64$ ). Similarly, the percentages of aneurysms treated (47.7\% [231] vs $44.9 \%$ [93], respectively; $\mathrm{p}=0.50)$, aneurysms clipped ( $48.5 \%$ [112] vs $57.0 \%$ [53], respectively; $p=0.49$ ), and aneurysms coiled $(51.5 \%$ [119] vs $43.0 \%$ [40], respectively; $p=0.13)$ did not differ between groups (Table 2). Altogether, 253 (52.3\%) aneurysms remained unruptured and unprotected in the VIH group, while 114 (55.1\%) aneurysms remained unruptured and unprotected in the non-VIH group $(\mathrm{p}=0.50)$. For the VIH and non-VIH groups, the mean sizes of the ruptured ( $7.2 \pm 0.3$ vs $7.8 \pm 0.6 \mathrm{~mm}$, respectively; $\mathrm{p}=0.27)$ and unruptured ( $3.4 \pm 0.2$ vs $3.2 \pm 0.2 \mathrm{~mm}$, respectively; $\mathrm{p}=0.40$ ) aneurysms did not differ (Table 2). The mean number of aneurysms per patient in the VIH and non-VIH groups was $2.75 \pm 0.09$ and $2.84 \pm 0.14$, respectively $(p=$ 0.60 ). The mean number of unruptured, unprotected aneurysms per patient in the VIH and non-VIH groups was $1.44 \pm 0.05$ and $1.56 \pm 0.10$, respectively $(\mathrm{p}=0.23)$.

For the VIH group, the most common locations for intracranial aneurysm (both ruptured and unruptured) were the middle cerebral artery (MCA) bi- or trifurcation (95 [19.6\%]), posterior communicating artery (69 [14.3\%]), and anterior communicating artery (60 [12.4\%]) (Table $3)$. Similarly, for the non-VIH group, the most common aneurysm locations were the MCA bi- or trifurcation (36 $[17.4 \%])$, posterior communicating artery $(35[16.9 \%])$, and anterior communicating artery (28 [13.5\%]) (Table 3).

\section{Fluid Balance}

There was no significant difference in daily fluid balance between the VIH and non-VIH patients over the initial 10-day period that therapy was initiated (Fig. 2). Furthermore, cumulative fluid balance over this 10-day 


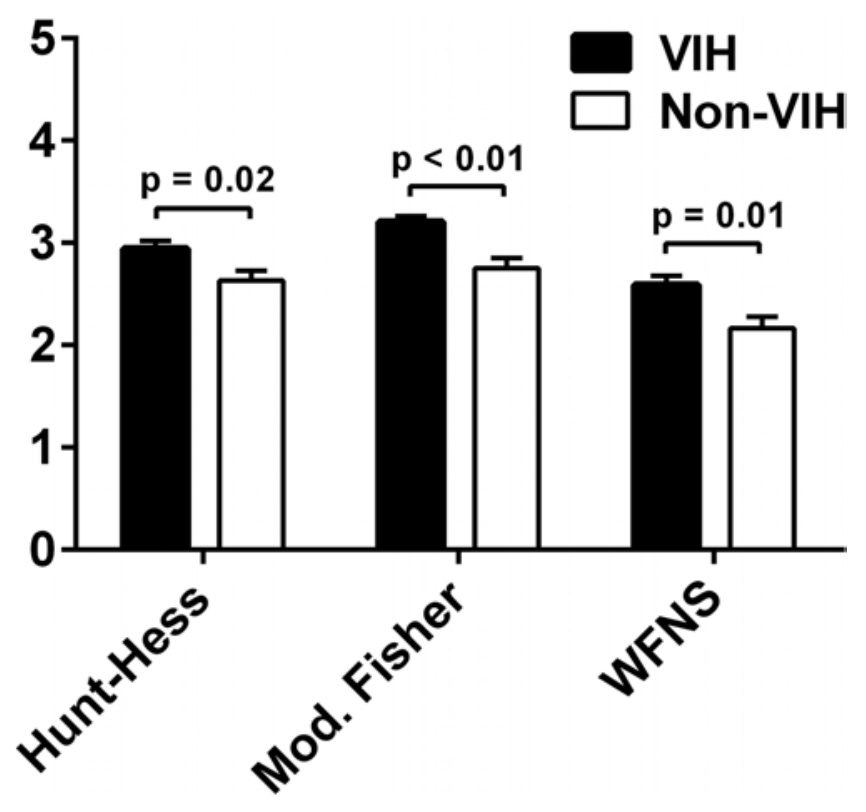

FIG. 1. Clinical (Hunt and Hess and WFNS grading scales) and radiographic (modified [Mod.] Fisher scale) SAH severity were compared between $\mathrm{VIH}(n=176)$ and non- $\mathrm{VIH}(\mathrm{n}=73)$ patients. Data represent the mean \pm SEM.

period did not differ between the VIH and non-VIH patients $(3146.2 \pm 296.4$ vs $2910.5 \pm 450.7 \mathrm{ml}$, respectively; $\mathrm{p}=0.67)$.

\section{Blood Pressure}

In the VIH group, both MAP and SBP were significantly increased at each 8-hour period relative to the nonVIH group (Fig. 3). The average relative increases in MAP over the 10-day period for the VIH and non-VIH groups were $125.1 \% \pm 1.0 \%$ and $98.2 \% \pm 1.2 \%$, respectively $(\mathrm{p}<$ $0.01)$. The average relative increases in SBP over the 10day period for the VIH and non-VIH groups were $125.6 \%$ $\pm 1.1 \%$ and $104.1 \% \pm 5.2 \%$, respectively $(\mathrm{p}<0.01)$. Therefore, VIH therapy resulted in a greater than $25 \%$ increase in both MAP and SBP from the baseline values. The average MAP upon admission (taken as the average of the first 3 blood pressure measurements) did not significantly differ between the VIH and non-VIH groups $(98.3 \pm 1.8 \%$ vs $98.9 \pm 1.6 \%$, respectively; $\mathrm{p}=0.89$ ).

The majority of patients in the VIH group (> 77\%) achieved MAP greater than $10 \%$ to $15 \%$ of their baseline levels. Specifically, 24 patients (13.6\%) achieved MAP $<10 \%$ above baseline, 16 patients $(9.1 \%)$ achieved MAP $10 \%-15 \%$ above baseline, 48 patients $(27.3 \%)$ achieved $15 \%-25 \%$ above baseline, 47 patients $(26.7 \%)$ achieved MAP 25\%-35\% above baseline, and 41 patients (23.3\%) achieved MAP > 35\% above baseline.

\section{Patient Outcomes}

In the VIH group, $36.9 \%$ of patients were discharged home, $46.5 \%$ were discharged to a rehabilitation center, $5.7 \%$ were discharged to a nursing home or long-term care facility, and $10.8 \%$ died or went home for hospice care. In the non-VIH group, $37.0 \%$ of patients were discharged
TABLE 2. Aneurysm characteristics*

\begin{tabular}{|c|c|c|c|}
\hline & VIH & Non-VIH & $\begin{array}{c}p \\
\text { Value }\end{array}$ \\
\hline Total no. & 484 & 207 & \\
\hline Ruptured $†$ & $182(37.6)$ & $74(35.7)$ & 0.64 \\
\hline Unruptured & $302(62.4)$ & $133(64.3)$ & 0.64 \\
\hline Treated $\ddagger$ & $231(47.7)$ & $93(44.9)$ & 0.50 \\
\hline Clipped & $112(48.5)$ & $53(57.0)$ & 0.49 \\
\hline Coiled & $119(51.5)$ & $40(43.0)$ & 0.13 \\
\hline $\begin{array}{l}\text { Unruptured, unprotected during } \\
\text { study period }\end{array}$ & $253(52.3)$ & $114(55.1)$ & 0.50 \\
\hline \multicolumn{4}{|l|}{ Mean size (mm) } \\
\hline Ruptured & $7.2 \pm 0.3$ & $7.8 \pm 0.6$ & 0.27 \\
\hline Unruptured & $3.4 \pm 0.2$ & $3.2 \pm 0.2$ & 0.40 \\
\hline \multicolumn{4}{|c|}{$\begin{array}{l}\text { * Values are presented as the number of aneurysms (\%). Mean values are } \\
\text { presented as the mean } \pm \text { SEM. } \\
\dagger \text { In some patients, multiple aneurysms were suspected of bleeding; in these } \\
\text { cases, all suspected aneurysms were treated. } \\
\text { I Includes both ruptured and unruptured aneurysms treated at the time of } \\
\text { surgery. }\end{array}$} \\
\hline
\end{tabular}

TABLE 3. Locations of intracerebral aneurysms

\begin{tabular}{|c|c|c|}
\hline \multirow[b]{2}{*}{ Location } & \multicolumn{2}{|c|}{ No. of Aneurysms (\%) } \\
\hline & VIH & Non-VIH \\
\hline All locations & 484 & 207 \\
\hline$A_{1}$ segment & $6(1.2)$ & $2(1.0)$ \\
\hline $\mathrm{ACoA}$ & $60(12.4)$ & $28(13.5)$ \\
\hline AChA & $24(5.0)$ & $16(7.7)$ \\
\hline Basilar apex & $20(4.1)$ & $11(5.3)$ \\
\hline Basilar-AICA & $1(0.2)$ & $1(0.5)$ \\
\hline Basilar artery & $5(1.0)$ & $1(0.5)$ \\
\hline Cavernous carotid artery & $16(3.3)$ & $6(2.9)$ \\
\hline Distal ACA & $25(5.2)$ & $11(5.3)$ \\
\hline Distal MCA & $9(1.9)$ & $4(1.9)$ \\
\hline Distal AICA & $0(0.0)$ & $0(0.0)$ \\
\hline Distal PICA & $2(0.4)$ & $0(0.0)$ \\
\hline Distal PCA & $0(0.0)$ & $0(0.0)$ \\
\hline Distal SCA & $4(0.8)$ & $0(0.0)$ \\
\hline ICA bifurcation & $26(5.4)$ & $7(3.4)$ \\
\hline ICA-posterior wall & $7(1.4)$ & $1(0.5)$ \\
\hline$M_{1}$ segment & $17(3.5)$ & $7(3.4)$ \\
\hline MCA bi/trifurcation & $95(19.6)$ & $36(17.4)$ \\
\hline Ophthalmic artery & $41(8.5)$ & $15(7.2)$ \\
\hline PCoA & $69(14.3)$ & $35(16.9)$ \\
\hline SCA-PCA & $8(1.7)$ & $7(3.4)$ \\
\hline Superior hypophyseal & $31(6.4)$ & $12(5.8)$ \\
\hline Vertebral-PICA & $9(1.9)$ & $6(2.9)$ \\
\hline Vertebral artery & $0(0.0)$ & $1(0.5)$ \\
\hline Other* & $9(1.9)$ & $0(0.0)$ \\
\hline
\end{tabular}

$\mathrm{ACh} A$ = anterior choroidal artery; $\mathrm{ACOA}=$ anterior communicating artery; $\mathrm{AICA}$ = anterior inferior cerebellar artery; $\mathrm{PCA}=$ posterior cerebral artery; $\mathrm{PCOA}=$ posterior communicating artery; PICA = posterior inferior cerebellar artery; SCA = superior cerebellar artery.

* Denotes either the carotid cave or petrous carotid. 


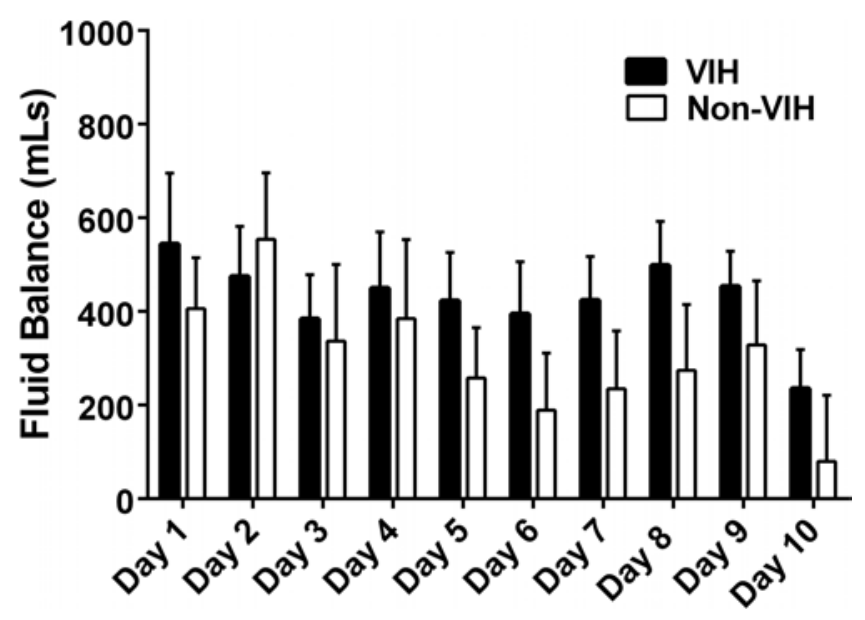

FIG. 2. Average daily fluid balance (e.g., Intake daily - Output $\left._{\text {dail }}\right)$ for VIH $(n=176)$ and non-VIH $(n=73)$ patients. For VIH patients, fluid balance was calculated during the first 10 days of induced hypertension and compared with the fluid balance of the non-VIH patients during Days $6-16$ of hospitalization. Posthemorrhage Day 6 was chosen as the starting date for the non-VIH group, given that the average start time of $\mathrm{VIH}$ therapy was posthemorrhage Day $6.39 \pm 0.27$. Data represent the mean \pm SEM.

home, $43.8 \%$ were discharged to a rehabilitation center, $9.6 \%$ were discharged to a nursing home or long-term care facility, and $9.6 \%$ died or went home for hospice care.

\section{New SAH From a Previously Unruptured, Unprotected Aneurysm}

We observed 1 new SAH from a previously unruptured, unprotected aneurysm in each group during the study period ( 1 of 176 patients vs 1 of 73 patients; $p=0.50$ ). Here, we describe the clinical course of the non-VIH patient who suffered a new SAH from a previously unruptured, unpro- tected aneurysm during the same hospitalization. We presented the VIH patient who experienced a new SAH from a previously unruptured, unprotected aneurysm during VIH in a previous report ${ }^{19}$ and will only briefly summarize our findings here.

\section{New SAH in a Non-VIH Patient}

A 70-year-old woman with a history of untreated hypertension presented with a Hunt and Hess Grade 2, modified Fisher Grade 4 SAH. Initial head CT showed diffuse SAH in the basal cisterns and mild ventriculomegaly (Fig. 4). Angiography revealed 2 aneurysms: a $10-\mathrm{mm}$ right superior hypophyseal artery aneurysm (presumably ruptured) and a 3-mm left anterior choroidal artery aneurysm (Fig. 5). The patient underwent coiling of the larger, right-sided aneurysm. During the procedure, a coil loop prolapsed into the parent artery, forming an acute thrombus that caused sluggish flow in the right internal carotid artery (ICA) and occlusion of the right anterior cerebral artery (ACA). After intraarterial ReoPro (abciximab), normal flow was reestablished. During the postprocedural period, she was maintained on therapeutic heparin infusion, as well as aspirin and clopidogrel. She developed a groin hematoma that caused a drop in hemoglobin ( $2 \mathrm{~g} / 24$ hours), but this did not alter her hemodynamic status or require transfusion. The patient was maintained on intravenous crystalloids to maintain a state of euvolemia. VIH therapy was not used, and her SBP and MAP did not significantly change from their baseline values.

On posthemorrhage Day 7, the patient experienced acute neurological decline, and repeat head CT showed a new SAH in the basilar cisterns with lateralization of the hemorrhage to the left sylvian fissure (Fig. 6). The patient was taken for coiling of the left anterior choroidal artery aneurysm, but the procedure was abandoned due to difficulties with catheter positioning and coil placement. A
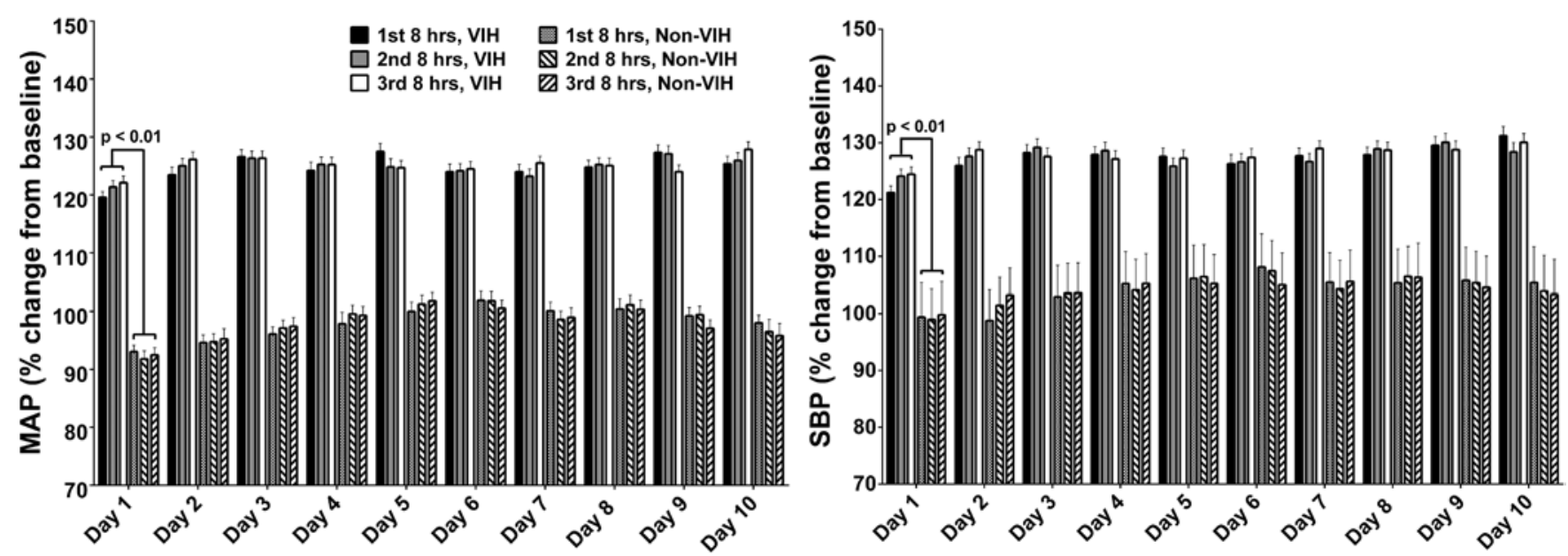

FIG. 3. Average MAP (left) and SBP (right) for VIH $(n=176)$ and non-VIH $(n=73)$ patients. MAP and SBP were averaged every 8 hours for $\mathrm{VIH}$ patients during the first 10 days of $\mathrm{VIH}$ therapy and compared with the average MAP and SBP for non-VIH patents during Days 6-16 of hospital admission, respectively. Posthemorrhage Day 6 was chosen as the starting date for the non-VIH group, given that the average start time for $\mathrm{VIH}$ therapy was posthemorrhage Day $6.39 \pm 0.27$. These values were reported as a mean percentage change from baseline \pm SEM (for VIH patients, the baseline was the average of the 3 hours prior to $\mathrm{VIH}$; for non-VIH patients, the baseline was the average of the 3 hours prior to data collection on posthemorrhage Day 6). The comparison bars and $p$ values displayed for Day 1 in both panels apply to all other days of treatment (e.g., Days 2-10) and are not displayed to avoid redundancy. 


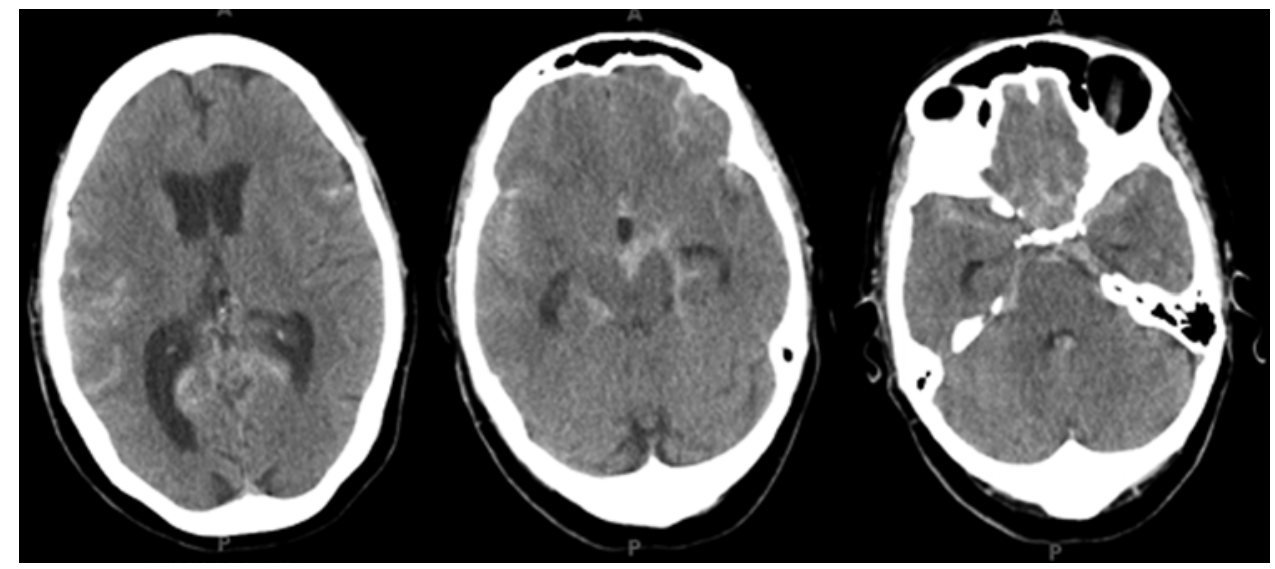

FIG. 4. Initial noncontrast head CT scans obtained in the non-VIH patient who developed a new SAH on posthemorrhage Day 7 , showing diffuse, thick SAH in the basilar cisterns. On the sections closer to the vertex, the SAH appears eccentric to the right sylvian fissure and sulci in the right frontoparietal areas. At the level of the midbrain, however, there appears to be a slight laterality of SAH to the left ambient and crural cisterns.

postprocedural angiogram, however, revealed spontaneous thrombosis of the aneurysm (Fig. 7). She returned to the neurosurgical intensive care unit for observation. Ultimately, her intracranial pressure became refractory to aggressive CSF diversion and medical management. Given her persistently poor neurological examination findings, her family elected to withdraw care and she died shortly thereafter.

\section{New SAH in a VIH Patient}

A 43-year-old woman with untreated hypertension presented with a Hunt and Hess Grade 3, modified Fisher Grade 4 SAH. Angiography showed 3 intracranial aneurysms: an irregular, broad-necked, 10-mm basilar apex aneurysm (presumably ruptured); a broad-necked, 7-mm right MCA bifurcation aneurysm; and a broad-necked, 8-mm right posterior communicating artery aneurysm. The patient underwent coiling of the basilar apex aneurysm without complications. During the postprocedural period, she received intravenous crystalloids to maintain a state of euvolemia to hypervolemia.

On posthemorrhage Day 7, she became increasingly somnolent. Head CT showed no acute changes. Cerebral angiography demonstrated near-complete occlusion of the basilar apex aneurysm with moderate vasospasm in the distal basilar artery and bilateral $\mathrm{A}_{1}$ and proximal $\mathrm{A}_{2} \mathrm{ACA}$ segments. The remaining aneurysms were unchanged in size and appearance. VIH therapy was started (in order to achieve a MAP > $120 \mathrm{~mm} \mathrm{Hg}$; baseline MAP 100-110 $\mathrm{mm} \mathrm{Hg}$ ), and there was some improvement in her mental status.

On posthemorrhage Day 12, the patient's mental status
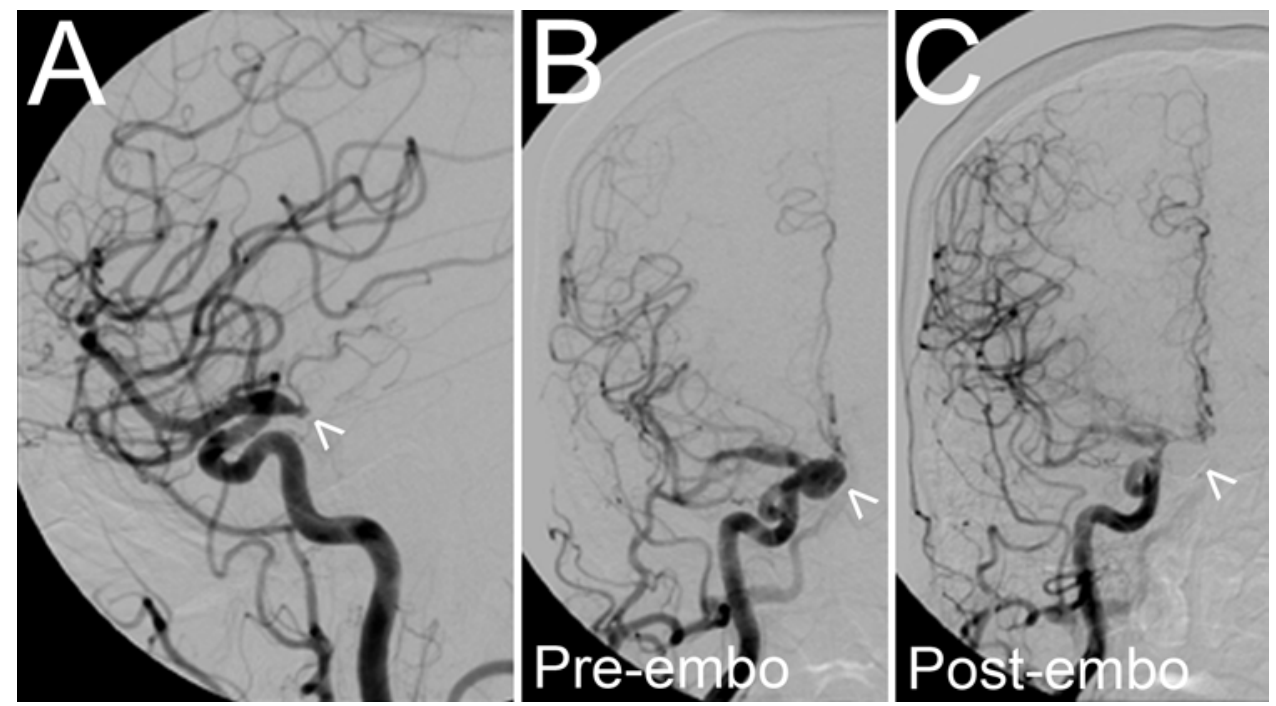

FIG. 5. Preembolization cerebral angiograms obtained in the non-VIH patient who developed a new SAH on posthemorrhage Day 7 with lateral view from left common carotid artery contrast injection $(A)$ and anteroposterior view from left common carotid artery contrast injection (B). Two intracranial aneurysms are present: a small left anterior choroidal artery aneurysm (A, arrowhead) and a larger, right superior hypophyseal artery aneurysm (B, arrowhead). Following endovascular embolization, the right superior hypophyseal aneurysm was almost completely obliterated (>95\%, C, arrowhead). embo = embolization. 


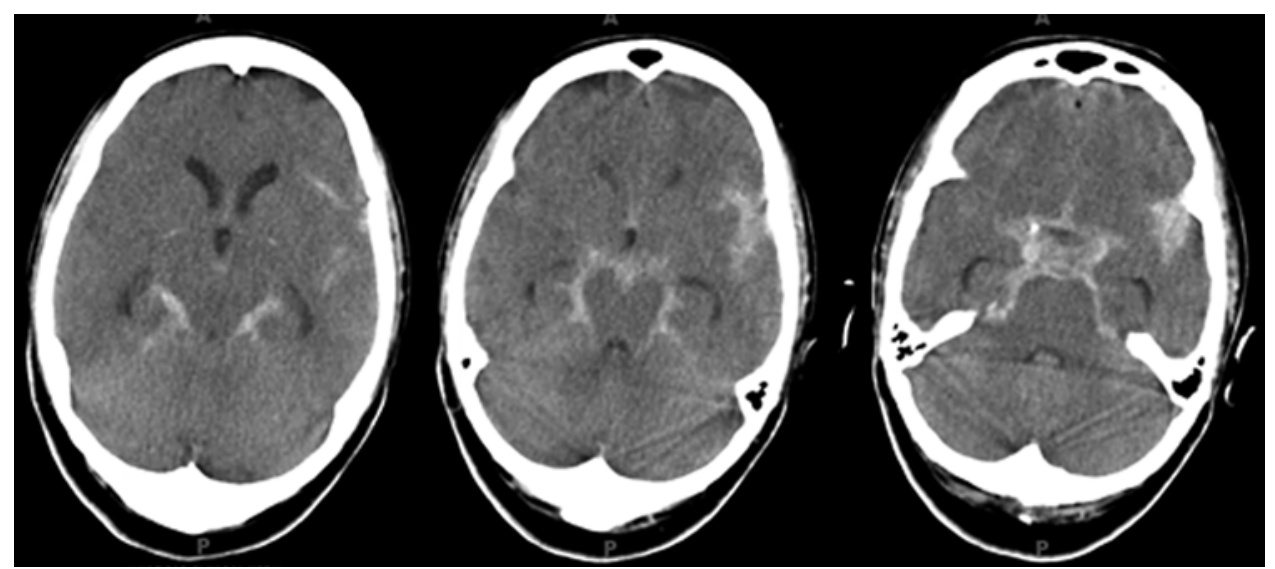

FIG. 6. Axial sections from a noncontrast head CT obtained on posthemorrhage Day 7, demonstrating a new, thick SAH localized to the basilar cisterns and left sylvian fissure.

abruptly deteriorated, and it was noted that pulsatile, arterial blood filled the ventriculostomy collection canister. Repeat head CT showed new SAH with intraventricular extension (greater on the right side than the left). Repeat angiography demonstrated severe vasospasm in the right $A_{1}, A_{2}$, and $M_{1}$ segments, as well as a new focal outpouching from the dome of the aneurysm in the right posterior communicating artery. This aneurysm was subsequently treated by coil embolization. After a prolonged hospital course, the patient made an excellent neurological recovery.

\section{Discussion}

In our cohort of $176 \mathrm{VIH}$ and 73 non-VIH patients, we observed no statistically significant difference in the incidence of new SAH between groups (1 of 176 patients vs 1 of 73 patients; $p=0.50)$. In the VIH group, 253 unruptured, unprotected aneurysms were treated with VIH for a total of 1870.6 days, resulting in a cumulative VIH treatment

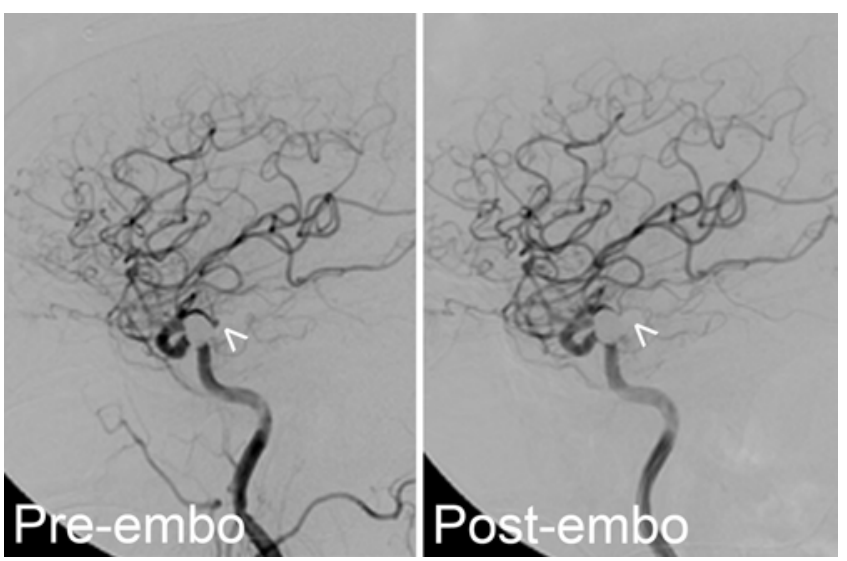

FIG. 7. Cerebral angiogram of the non-VIH patient who developed a new SAH on posthemorrhage Day 7 with lateral views from left common carotid artery contrast injection before (left) and after (right) attempted coil embolization of a small anterior choroidal artery aneurysm. Several coils were initially placed within the aneurysm, but subsequently removed due to intraprocedural technical difficulties. At the end of the procedure, however, the aneurysm spontaneously thrombosed (arrowheads). time of 5.12 years. These data strongly support the notion that VIH therapy is safe in SAH patients and suggest that the risk of SAH from a small, unruptured, unprotected aneurysm during VIH therapy is similar to the documented risk for small unruptured aneurysms in patients with a prior history of SAH ( $\sim 0.5 \%$ annual rupture rate).$^{25}$

There are multiple aspects of our study that support our principal conclusion that VIH is safe for SAH patients with small, unruptured, unprotected aneurysms. First, our series is the largest reported to date and includes data from 5 high-volume cerebrovascular neurosurgical referral centers. The addition of our 176 patients to the literature more than doubles the number of previously reported cases (Table 4). Second, our study includes a control group of patients who harbored coexisting unruptured, untreated aneurysms but did not undergo VIH. This is the second study to have included this important control group, albeit with far greater numbers: 73 control patients (and 176 VIH-treated patients) in our series versus 16 control patients (and 29 VIH-treated patients) in the series by Kim et al. ${ }^{13}$ (Table 4). The importance of this control group is exemplified by our control patient who suffered a new SAH at 7 days after initial presentation. Third, we meticulously documented hemodynamic parameters during VIH therapy. Fourth, our study focused on the most effective and relevant aspect of triple-H therapy: induced hypertension. ${ }^{4,18}$

Other smaller, single-institution series have examined the safety of VIH in the setting of SAH and coexisting, unruptured, unprotected aneurysms (Table 4). Platz et al. ${ }^{16}$ reported a series of $41 \mathrm{SAH}$ patients with coexisting, unruptured, unprotected aneurysms who underwent triple-H therapy for symptomatic vasospasm. Of these, 32 were treated with VIH therapy and had sufficient hemodynamic values to permit analysis. None of these 32 patients suffered a new SAH. Kim et al. ${ }^{13}$ reported a series of 29 SAH patients with coexisting, unruptured, unprotected aneurysms who underwent VIH therapy (Table 4). These patients were compared with a control group of $16 \mathrm{SAH}$ patients who did not receive VIH. No patient from either group suffered a new SAH. Similarly, Hoh et al. ${ }^{8}$ reported no new instances of SAH in their series of $40 \mathrm{SAH}$ patients with coexisting, unruptured, unprotected aneurysms who underwent VIH therapy. Swift and Solomon ${ }^{22}$ also report- 
TABLE 4. Reports of patients with SAH and unruptured, unprotected aneurysms who received VIH therapy

\begin{tabular}{|c|c|c|c|c|}
\hline Authors \& Year & No. of Patients & New SAH & Notes & Conclusion \\
\hline Present study & 176 & Yes; 1 patient & $\begin{array}{l}\text { Multiinstitutional study; } 73 \text { non-VIH patients used } \\
\text { as comparison group; meticulous blood pressure } \\
\text { documentation }\end{array}$ & VIH probably safe \\
\hline Hoh et al., 2002 & 40 & No & & VIH probably safe \\
\hline Platz et al., 2011 & 32 & No & & VIH probably safe \\
\hline Kim et al., 2006 & 29 & No & $\begin{array}{l}\text { Single institutional study; } 16 \text { non-VIH patients used } \\
\text { as comparison group }\end{array}$ & VIH probably safe \\
\hline Swift et al., 1992 & 8 & No & & $\begin{array}{l}\text { Not specifically } \\
\text { addressed }\end{array}$ \\
\hline Kassell et al., 1990 & 6 & No & $\begin{array}{l}\text { Reference prior study where patient w/ SAH \& a } \\
\text { previously unruptured giant ICA aneurysm had } \\
\text { new, fatal SAH; unclear if patient was treated w/ } \\
\text { VIH therapy }\end{array}$ & $\begin{array}{l}\text { Not specifically } \\
\text { addressed }\end{array}$ \\
\hline Aiyagari et al., 2001 & 5 & No & & $\begin{array}{l}\text { Not specifically } \\
\text { addressed }\end{array}$ \\
\hline Anda et al., 2006 & 5 & No & & $\begin{array}{l}\text { Not specifically } \\
\text { addressed }\end{array}$ \\
\hline
\end{tabular}

ed no new instances of SAH among their 8 SAH patients with coexisting, unruptured, unprotected aneurysms who underwent VIH therapy. Kassell et al. ${ }^{11}$ reported a series of 6 SAH patients with coexisting, unruptured, unprotected aneurysms who underwent VIH therapy. None suffered a new SAH, although the authors referenced a prior SAH patient with a previously unruptured, unprotected, giant ICA aneurysm who suffered a new fatal SAH during triple-H therapy. ${ }^{10}$ It was unclear, however, whether this patient was treated with VIH or hypervolemia alone.

In total, our review of the literature identified $301 \mathrm{SAH}$ patients with coexisting, unruptured, unprotected aneurysms who underwent VIH therapy: 176 in the present series and 125 included in past reports. ${ }^{1,2,8,11,13,16,22}$ Of these 301 patients, only 1 patient (in the present report) experienced a new SAH from a previously unruptured aneurysm. Given that the annual risk of the rupture of a small, unruptured, intracranial aneurysm in a patient with a history of SAH is estimated to be approximately $0.5 \%,{ }^{25}$ these cumulative data strongly indicate that the natural history of unruptured, unsecured aneurysms is not significantly affected by a short course of VIH. Given the substantial morbidity associated with untreated vasospasm-induced DCI, ${ }^{12}$ we strongly advocate for the use of VIH in SAH patients with coexisting, unruptured, unprotected aneurysms who develop signs and symptoms of DCI.

Our study has multiple limitations. First, this is a retrospective analysis and therefore is subject to the biases inherent to the study design. Second, because the incidence of new SAH from a small, previously unruptured, unprotected aneurysm in VIH-treated patients is rare, our study may be underpowered for definitively determining if a significant difference between VIH and non-VIH patients exists in terms of such an infrequent clinical event. Third, while we examined the risk of new SAH from an unruptured, unprotected aneurysm in the period immediately following SAH, the long-term consequences of VIH and its effects on aneurysm rupture were not specifically examined. Fourth, the mean size of the unruptured, unpro- tected aneurysms in our study was significantly smaller than that of the ruptured aneurysms. As such, bias related to aneurysm size and rupture rate may exist. Our study results, therefore, primarily pertain to smaller, unruptured aneurysms and cannot be extrapolated to large, highly irregular, or giant unruptured aneurysms. Fifth, there was a small, but statistically significant, difference in clinical and radiographic SAH severity between the 2 groups (greater in the VIH group than the non-VIH group). While this observation makes logical sense, it is unclear if this variable could have impacted the chance of a new SAH. Sixth, while the magnitude of VIH therapy (e.g., increase in MAP relative to baseline) in our study was comparable to other large studies on triple-H therapy in aneurysmal SAH patients, ${ }^{4}$ our results may not necessarily apply to patients where the degree of VIH therapy is more aggressive. Finally, it is conceivable that for both VIH and non-VIH patients who experienced a new SAH during the study period that these events may actually represent rebleeding from a previously ruptured, but untreated, aneurysm (e.g., the aneurysm that was initially treated was not the aneurysm that ruptured). Though this is unlikely given that past studies show that larger and more irregular aneurysms are typically the source of SAH in patients with multiple aneurysms, ${ }^{5}$ and the aneurysms that we initially treated were larger and more irregular than those that were not treated, definitely establishing which aneurysm had ruptured was not possible by visual inspection since in both cases the aneurysms were treated with endovascular therapy. However, even if we conservatively exclude the non-VIH patient with recurrent SAH and include the VIH patient with recurrent SAH from our statistical analysis, there is still no significant difference in the incidence of new SAH between the 2 groups ( 1 of 176 patients vs 0 of 73 patients; $\mathrm{p}=1.00)$.

\section{Conclusions}

For small, unruptured, unprotected intracranial an- 
eurysms in SAH patients, aneurysm rupture during VIH therapy is rare. Our data indicate that VIH therapy is likely safe in this setting and should not be withheld given the significant morbidity and mortality associated with vasospasm-induced DCI.

\section{Acknowledgment}

We would like to acknowledge Michael Wallendorf, PhD, senior statistical analyst from Washington University in St. Louis, Division of Biostatistics, for assisting with the statistical analysis.

\section{References}

1. Aiyagari V, Cross DT III, Deibert E, Dacey RG Jr, Diringer MN: Safety of hemodynamic augmentation in patients treated with Guglielmi detachable coils after acute aneurysmal subarachnoid hemorrhage. Stroke 32:1994-1997, 2001

2. Anda T, Yonekura M, Baba H, Suyama K, Toda K, Kamada $\mathrm{K}$, et al: Factors affecting rapid growth of unruptured cerebral aneurysms during the acute stage of subarachnoid hemorrhage. Neurol Res 28:165-171, 2006

3. Baek SM, Makabali GG, Bryan-Brown CW, Kusek JM, Shoemaker WC: Plasma expansion in surgical patients with high central venous pressure (CVP); the relationship of blood volume to hematocrit, CVP, pulmonary wedge pressure, and cardiorespiratory changes. Surgery 78:304-315, 1975

4. Dankbaar JW, Slooter AJ, Rinkel GJ, Schaaf IC: Effect of different components of triple-H therapy on cerebral perfusion in patients with aneurysmal subarachnoid haemorrhage: a systematic review. Crit Care 14:R23, 2010

5. Dhar S, Tremmel M, Mocco J, Kim M, Yamamoto J, Siddiqui $\mathrm{AH}$, et al: Morphology parameters for intracranial aneurysm rupture risk assessment. Neurosurgery 63:185-197, 2008

6. Ellamushi HE, Grieve JP, Jäger HR, Kitchen ND: Risk factors for the formation of multiple intracranial aneurysms. $\mathbf{J}$ Neurosurg 94:728-732, 2001

7. Frontera JA, Claassen J, Schmidt JM, Wartenberg KE, Temes $\mathrm{R}$, Connolly ES Jr, et al: Prediction of symptomatic vasospasm after subarachnoid hemorrhage: the modified fisher scale. Neurosurgery 59:21-27, 2006

8. Hoh BL, Carter BS, Ogilvy CS: Risk of hemorrhage from unsecured, unruptured aneurysms during and after hypertensive hypervolemic therapy. Neurosurgery 50:1207-1212, 2002

9. Hunt WE, Hess RM: Surgical risk as related to time of intervention in the repair of intracranial aneurysms. J Neurosurg 28:14-20, 1968

10. Kassell NF, Peerless SJ, Drake CG: Reversal of ischemic deficits by increasing systemic arterial pressure. Stroke 9:104-105, 1978 (Abstract)

11. Kassell NF, Peerless SJ, Durward QJ, Beck DW, Drake CG, Adams HP: Treatment of ischemic deficits from vasospasm with intravascular volume expansion and induced arterial hypertension. Neurosurgery 11:337-343, 1982

12. Kassell NF, Torner JC, Haley EC Jr, Jane JA, Adams HP, Kongable GL: The International Cooperative Study on the Timing of Aneurysm Surgery. Part 1: Overall management results. J Neurosurg 73:18-36, 1990

13. Kim HS, Park CW, Chun YI, Kim WK, Lee SG, You CJ, et al: Hemorrhagic risk of unsecured, unruptured aneurysms during hypervolemic hypertensive therapy in patient with multiple intracranial aneurysms. Korean Journal Cerebrovasc Surg 8:178-183, 2006
14. Locksley HB, Sahs AL, Knowler L: Report on the cooperative study of intracranial aneurysms and subarachnoid hemorrhage. Section II. General survey of cases in the central registry and characteristics of the sample population. J Neurosurg 24:922-932, 1966

15. Nieuwkamp DJ, Setz LE, Algra A, Linn FH, de Rooij NK, Rinkel GJ: Changes in case fatality of aneurysmal subarachnoid haemorrhage over time, according to age, sex, and region: a meta-analysis. Lancet Neurol 8:635-642, 2009

16. Platz J, Güresir E, Vatter H, Berkefeld J, Seifert V, Raabe A, et al: Unsecured intracranial aneurysms and induced hypertension in cerebral vasospasm: is induced hypertension safe? Neurocrit Care 14:168-175, 2011

17. Qureshi AI, Suarez JI, Parekh PD, Sung G, Geocadin R, Bhardwaj A, et al: Risk factors for multiple intracranial aneurysms. Neurosurgery 43:22-27, 1998

18. Raabe A, Beck J, Keller M, Vatter H, Zimmermann M, Seifert V: Relative importance of hypertension compared with hypervolemia for increasing cerebral oxygenation in patients with cerebral vasospasm after subarachnoid hemorrhage. J Neurosurg 103:974-981, 2005

19. Reynolds MR, Mollman ME, Murphy RK, Arias EJ, Zipfel GJ: Acute rupture of a previously unruptured, untreated intracerebral aneurysm during induced hypertension for vasospasm in subarachnoid hemorrhage. J Spine Neurosurg 3:5, 2014

20. Rinne J, Hernesniemi J, Puranen M, Saari T: Multiple intracranial aneurysms in a defined population: prospective angiographic and clinical study. Neurosurgery 35:803-808, 1994

21. Sen J, Belli A, Albon H, Morgan L, Petzold A, Kitchen N: Triple-H therapy in the management of aneurysmal subarachnoid haemorrhage. Lancet Neurol 2:614-621, 2003

22. Swift DM, Solomon RA: Unruptured aneurysms and postoperative volume expansion. J Neurosurg 77:908-910, 1992

23. Toussaint GP, Burgess JH, Hampson LG: Central venous pressure and pulmonary wedge pressure in critical surgical illness. A comparison. Arch Surg 109:265-269, 1974

24. Weidauer S, Lanfermann H, Raabe A, Zanella F, Seifert V, Beck J: Impairment of cerebral perfusion and infarct patterns attributable to vasospasm after aneurysmal subarachnoid hemorrhage: a prospective MRI and DSA study. Stroke 38:1831-1836, 2007

25. Wiebers D, Whisnant J, Forbes G, Meissner I, Brown R, Piepgras D, et al: Unruptured intracranial aneurysms - risk of rupture and risks of surgical intervention. N Engl J Med 339:1725-1733, 1998

\section{Author Contributions}

Conception and design: Zipfel, Reynolds. Acquisition of data: all authors. Analysis and interpretation of data: all authors. Drafting the article: Zipfel, Reynolds. Critically revising the article: Zipfel, Reynolds, Amin-Hanjani, Lanzino, Hoh, Bendok. Reviewed submitted version of manuscript: all authors. Statistical analysis: Reynolds. Administrative/technical/material support: Reynolds. Study supervision: Zipfel, Reynolds.

\section{Correspondence}

Gregory J. Zipfel, Department of Neurological Surgery, Washington University School of Medicine, Campus Box 8057, 660 South Euclid Ave., St. Louis, MO 63110. email: zipfelg@ wustl.edu. 